\title{
Política social e trabalho familiar: questões emergentes no debate contemporâneo
}

\author{
Social policy and family work: an emerging \\ issue in the contemporary debate
}

\author{
Regina Célia Tamaso Mioto \\ Assistente social, doutora em Saúde Mental-Unicamp; professora da Universidade \\ Católica de Pelotas/RS, Brasil; bolsista de Produtividade em Pesquisa/CNPq.
}

regina.mioto@gmail.com

\begin{abstract}
Resumo: O artigo debate a contraditória relação entre família e política social, evidenciando a questão do trabalho familiar. Discute seus aspectos históricos e conceituais e problematiza a questão da proteção social no capitalismo contemporâneo. Nesse contexto, enfatiza a cisão entre o mundo da produção e o da reprodução, bem como a incorporação do trabalho familiar pela política social. Apresenta a síntese integradora, de pesquisa bibliográfica, construída através do diálogo com o material examinado.
\end{abstract}

Palavras-chave: Política social. Trabalho familiar. Família. Capitalismo.

\begin{abstract}
This article aims at contributing to further debate about the relation between family and social policy, highlighting family work. It starts discussing its historical and conceptual aspects and discusses the issue of social protection in contemporary capitalism. In this context it emphasizes the split between the production and the reproduction world, as well as the incorporation of family work in the social policy debate. The integrating synthesis derives from the bibliography material, which makes it possible to through dialogue with the examined material.
\end{abstract}

Keywords: Social policy. Family work. Family. Capitalism.

\section{Introdução}

partir dos anos 1970, nos países de capitalismo central, e dos anos
1990, nos países latino-americanos, os estudos empreendidos
quanto à posição da família na política social têm aberto um campo de indagações bastante amplo no que se refere à clássica cisão entre o mundo da produção e o da reprodução. Nesse contexto, o debate sobre a 
família é retomado sob várias perspectivas, uma vez que a política social tem o papel fundamental de mediar e estruturar as relações estabelecidas pela família com outras esferas da sociedade, como Estado, trabalho e mercado. Dentre tais indagações e perspectivas analíticas, a questão do trabalho familiar ganha visibilidade, na medida em que sua incorporação pela política social se efetiva de diferentes formas no âmbito das transformações, tanto do trabalho quanto da família, no contexto da crise atual do capitalismo. A intensificação dos mecanismos de privatização da seguridade social, por exemplo, como procedimento essencial para o processo de acumulação capitalista, evidencia a família como um importante canal para ativação desses mecanismos, especialmente quando envolve a questão dos cuidados aos seus membros dependentes. Dessa forma, ela é recolocada como um elemento-chave na configuração dos sistemas de proteção social. Isso ocorre justamente no momento em que se aumenta a capacidade do capitalismo de mercantilizar as atividades humanas e em que os serviços são alvo importante de atividades lucrativas.

Considerando essa conjuntura, o presente artigo apresenta parte da síntese integradora da pesquisa bibliográfica desenvolvida sobre o tema: política social, família e trabalho familiar. ${ }^{1}$ A síntese integradora consiste na etapa final da pesquisa bibliográfica e decorre da análise e reflexão sobre os documentos pesquisados. Nela, o pesquisador constrói, com o material bibliográfico, um diálogo que possibilita indagar, explorar, refletir e propor soluções. O material pesquisado consistiu-se em textos publicados no âmbito das políticas de seguridade social e das políticas de conciliação entre trabalho e família publicados em periódicos nacionais e internacionais de

1. A pesquisa bibliográfica é parte da pesquisa Política Social, Família e Trabalho Familiar: proposições e percursos analíticos (CNPq, Processo n. 304540/2013-7), que foi desenvolvida em quatro etapas: 1) elaboração de um plano de pesquisa para se buscar respostas aos problemas colocados; 2) investigação das soluções relacionadas à coleta da documentação em momentos distintos e sucessivos, ou seja, levantamento da bibliografia e das informações contidas nessa bibliografia de acordo com o problema de pesquisa; 3) análise explicativa das soluções, que se refere a uma leitura crítica do pesquisador sobre os dados levantados para explicar, discutir, justificar os dados, fatos e informações contidas no material pesquisado; 4) síntese integradora, que consiste na etapa final do processo e decorre da análise e reflexão sobre os documentos (Salvador, 1986). 
língua espanhola e italiana. Outras referências foram encontradas em dissertações de mestrado, teses de doutorado e livros que versam sobre essa temática. Além disso, outras bases de informações foram consultadas, como: Scielo, Lilacs, bibliotecas virtuais, como a do Ipea, Cepal, Ministério da Saúde, OIT e Clacso.

Por meio dos resultados deste estudo, busca-se contribuir para o aprofundamento do debate sobre a temática proposta, colocando em evidência o trabalho familiar. Nesse sentido, o artigo articula, inicialmente, a discussão sobre o trabalho familiar, privilegiando seus aspectos históricos e conceituais. Em seguida, ainda em uma perspectiva sócio-histórica, problematiza a proteção social no contexto da crise do capitalismo contemporâneo, enfatizando a cisão entre o mundo da produção e o da reprodução, bem como a incorporação do trabalho familiar no debate da política social.

\section{Família e trabalho familiar}

Analisar o trabalho familiar implica reportar a grande cisão entre o mundo do trabalho e o da família. Historicamente, a mudança fundamental ocorrida com o advento da família burguesa foi o rompimento com uma família profundamente identificada - tanto na aristocracia como na burguesia mercantil - com uma intensa e visível atividade econômica. Nessa época, tratados econômicos consideravam a economia doméstica, a comercial e a financeira como contínuas para a configuração de uma família "separada" da economia empresarial e financeira. Assim, nasce uma família identificada como "instância privada", isenta de responsabilidades públicas e, ao mesmo tempo, com disponibilidade de recursos privados com base na criação e no controle de um capital privado. Em outras palavras, sem a obrigação de responder às consequências sociais e coletivas do próprio processo de circulação e de acumulação de capital; consequentemente, cortando os vínculos de reciprocidade. Isso marca uma assimetria entre as famílias detentoras do capital privado e as famílias que para essas trabalhavam. Essa separação provocou o estabelecimento de uma visão da família des- 
vinculada do trabalho e das relações econômicas. Parsons, que expressa bem essa visão, define a família como sendo o lugar dos afetos e dos processos de socialização. Essa perspectiva foi amplamente aceita pelos estudiosos da família (mesmo os não funcionalistas), em cujos estudos os vínculos com o trabalho e a economia passaram a aparecer ora através do consumo, ora em relação às famílias pobres. Estas, por sua vez, eram vistas por meio da sua privação de recursos e de energias, sem que se permitisse, portanto, o pleno desenvolvimento de sua dimensão relacional e socializadora (Saraceno, 1996; Seccombe, 1997).

Para Saraceno (1996), o processo de separação entre trabalho e família não ocorreu igualmente para todas as classes, considerando tanto as famílias que ainda são unidades produtivas (como as vinculadas à produção agrícola e à produção artesanal) quanto as dos trabalhadores assalariados. Para a autora, essas famílias continuaram, ao longo do tempo, sendo uma unidade econômica para a qual confluem rendimentos de diferentes fontes destinados a uma "bolsa comum", em geral administrada pela mulher/dona da casa. Isto é, embora os ganhos, particularmente os salariais, sejam individuais, o direito de administrá-los e de gastá-los é da família, ou seja, é coletivo. Porém isso não significa igualdade nem em relação às necessidades de solidariedade nem quanto à decisão de como gastar o "dinheiro de todos". Nesse contexto, a economia assalariada aprofunda desigualdades dentro da família a partir da divisão entre os que recebem salário e os que não recebem. Além disso, gera desequilíbrios e tensões entre os seus membros, especialmente entre os que ganham dinheiro de forma direta e os que o ganham de forma indireta, quer dizer, através do valor adjunto do trabalho doméstico.

No entanto, a complexidade instaurada por meio das relações entre família, trabalho e economia, paradoxalmente, através de sua separação no capitalismo industrial, permaneceu, em teoria, intocada, durante muito tempo. Especialmente sobre o trabalho, os estudos se concentraram na esfera da produção, e apenas no final do século XX, "la identificación tradicional entre trabajo y empleo asalariado empieza a ser cuestionada por la observación empírica que da cuenta de una gran diversidad de formas de trabajo, tanto mercantiles como no mercantiles" (Aguirre, 2009, p. 13). 
A partir da década de 1970, o debate sobre família e trabalho passa a acontecer, particularmente no escopo dos estudos feministas de orientação marxista, ${ }^{2}$ quando se colocou em pauta a questão do trabalho da mulher. Isso criou novas possibilidades de análise sobre a família, não só na sua relação com o mercado/mercado de trabalho, mas também na sua relação com o Estado. Além do mais, deu visibilidade, inclusive, ao fato de que a família, por meio do trabalho não remunerado da mulher, estruturou-se como um dos pilares do Estado de bem-estar social em muitos países. Ou seja, a família nuclear composta de homem, mulher e filhos, calcada na divisão sexual do trabalho - o "male breadwinner model" —, não é apenas uma unidade social fundamental para a sociedade, mas é também uma unidade econômica de distribuição de bens e serviços (Saraceno, 1996; Paulilo, 2004; Aguirre, 2009; Letablier, 2007; Pietro, 2007; e Martinez-Franzoni, 2008). Nas últimas décadas do século XX, com a entrada massiva das mulheres no mercado de trabalho e com a instauração das famílias de dupla carteira, bem como com as transformações nas configurações familiares e na pirâmide demográfica, o trabalho doméstico passa a ser fortemente tematizado.

De acordo com Gelinski e Pereira (2005), o debate sobre o trabalho doméstico iniciou-se com base em dois aspectos principais: um se refere à conceituação a respeito de sua natureza e as relações com o modo de produção capitalista; o outro se relaciona à posição de classe das mulheres e à sua relação com o movimento socialista. Em direção similar, Meil (2004) indica que o debate sobre o trabalho doméstico, no bojo da teoria social de Marx, também se centrou em dois aspectos: um se relaciona à natureza desse trabalho (produtivo ou improdutivo); o outro, à afirmação do trabalho doméstico

2. Segundo Moraes (2000, p. 97), "a perspectiva feminista ressalta a dimensão da opressão universal sobre as mulheres, guardadas as diferenças regionais e culturais, e busca nas estruturas objetivas as marcas inequívocas da desigualdade: as mulheres ganham menos e trabalham mais, no conjunto da população mundial, por exemplo. O marxismo, por sua vez, é a teoria que nos ajuda a entender a natureza íntima do capitalismo, a lógica de seu desenvolvimento, revolucionando permanentemente as condições de produção, especialmente através do aumento da produtividade, o que, por sua vez, determina a proletarização da maior parte da humanidade. Que existe uma questão da mulher não há dúvidas: os homens ainda concentram o poder econômico e político na maior parte do mundo, e as mulheres persistem sendo as grandes responsáveis pela família e pelo cuidar dos filhos, da casa e, cada vez mais, das finanças da família". 
como uma forma específica de produção (ou não) e suas relações com o modo de produção capitalista. ${ }^{3}$ Esse intenso debate, segundo o autor, recolocou o papel econômico da família em contraposição à ideia hegemônica no campo econômico de que ela é apenas unidade de consumo ou de oferta de força de trabalho. Afirma-se então a família como unidade de produção de bens e serviços fundamentais para o bem-estar individual e dos membros da unidade familiar. Enfim, essa perspectiva, ainda segundo o autor, permitiu evidenciar que a economia segue "incrustrada" dentro da família.

Nesse sentido, uma das chaves importantes desse debate está no reconhecimento do trabalho no âmbito da reprodução, e não apenas no campo da produção. Além disso, esse reconhecimento explicita a complexidade da inter-relação família/mulher e trabalho/economia, que se realiza tanto a partir do trabalho remunerado, quanto do não remunerado - ambos fundamentais na sustentação da subsistência e do bem-estar dos membros de uma sociedade. ${ }^{4}$ De acordo com Hernández Bello (2009), a contribuição econômica e social do trabalho doméstico não apenas colocou esse tipo de trabalho como central na discussão das políticas públicas, como também implicou a necessidade de sua valoração. Dessa forma, a quantificação da produção doméstica passou a ser uma preocupação que tem ensejado inúmeros estudos com o propósito de calcular o valor dessa produção a partir do tempo dedicado às tarefas domésticas e ao cuidado. ${ }^{5}$ Mais do que isso, existe um esforço

3. Embora essa questão não seja objeto da discussão deste projeto, uma referência sobre esse debate pode ser encontrada também em Iasi (2007), no seu texto sobre trabalho doméstico e valor. Nele, o autor discute, a partir das distinções de Marx sobre processo de trabalho, as diferentes tendências dos autores ao apreenderem o trabalho doméstico. Ou seja, o trabalho doméstico aparece: como simples processo de produção de valores de uso e, portanto, não produtor de valor; como processo de produção de valor, na medida em que produz mercadoria ao compor a mercadoria força de trabalho; e como um processo que contribui indiretamente na produção de mais-valia. Para o autor, o trabalho doméstico é uma forma particular de trabalho, que produz valor. Para ele, embora o trabalho doméstico não seja produtor de mais-valia, também não é apenas produtor de valores de uso.

4. Sobre a realidade brasileira consultar: Araújo e Scalon (2005).

5. Considerações acerca da incorporação do trabalho de reprodução, no campo das economias nacionais, podem ser encontradas na análise dos economistas brasileiros Melo, Considera e Di Sabbato (2007), realizada no artigo "Os afazeres domésticos contam". Merecem destaque também os trabalhos de Batthyány e Scuro (2010); de Aguirre (2009) sobre o uso do tempo e desigualdade de gênero no trabalho não remunerado com 
de correlação com outras fontes de provisão de bem-estar, como a do trabalho assalariado e das prestações sociais públicas para as diferentes classes sociais (Meil, 2004).

A discussão sobre o trabalho doméstico centrou-se também nas categorias de trabalho produtivo e reprodutivo. Porém, com o aprofundamento dos estudos sobre o trabalho na esfera doméstica, fortaleceu-se a utilização da nomenclatura trabalho remunerado, ou pago, e trabalho não remunerado, ou não pago. Essa opção, proposta por Benería (1999), vincula-se a fatores de ordem prática e conceitual ao considerar, por um lado, o crescente processo de mercantilização do trabalho reprodutivo nas nossas sociedades, que, dessa forma, passa a ser trabalho remunerado. Por outro lado, há o fato de o trabalho doméstico ter componentes que fogem à égide estrita de trabalho reprodutivo, ainda que sejam atividades que auxiliem a reprodução da força de trabalho. Isso também ocorre porque comporta atividades que não são essencialmente reprodutivas, como é o caso das reformas e dos arranjos das casas ou mesmo do trabalho comunitário.

Outro avanço que merece destaque nesse debate é o processo de desagregação das atividades realizadas pela família, especialmente entre o trabalho doméstico e o trabalho de cuidado. Tal desagregação é considerada importante, pois, além de dar maior visibilidade ao trabalho, permite também colocar na pauta das políticas públicas as atividades que seriam passíveis de desfamiliarização e a forma como seria possível realizá-las (Aguirre, 2009). Nesse contexto, ganha corpo a questão do cuidado, que acabou se constituindo também um campo específico de produção teórica, denominado economia do cuidado. Assim, a tentativa de quantificar esse campo e dar-lhe visibilidade na área econômica vai além dos estudos referentes estritamente à família. ${ }^{6}$ De maneira geral, o cuidado tem sido apresentado pelos estudiosos europeus como um conceito polissêmico, vinculado à reprodução e

base na realidade uruguaia. Além disso, Izquierdo (2008), ao levantar uma instigante reflexão conceitual acerca de trabalho produtivo a partir do tripé bem-estar, atividade econômica e contas nacionais, evidencia também a questão do trabalho não remunerado.

6. Sobre esse tema, consultar Izquierdo (2003) e Carrasco (2011). 
desenvolvido na família, e tem seguido diferentes tendências teóricas (Letablier, 2007). Hernández Bello (2009, p. 175), ao empreender esse debate no campo da saúde, entende que:

Los cuidados domésticos, informales o profanos son aquellos que la red social cercana presta a personas enfermas o discapacitadas, e implican tareas múltiples y simultáneas de atención personal, médica, doméstica y de enlace entre los ámbitos público y privado, cuya magnitud y complejidad dependen de la naturaleza de la atención y de las relaciones entre la demanda y la disponibilidad respecto de las características socioeconómicas y culturales de quienes los realizan.

Nesse sentido, Saraceno (1996) dá um passo além no processo de desagregação das atividades familiares ao propor o termo trabalho familiar. Para ela, o trabalho familiar compreende o conjunto das atividades desenvolvidas pela família no processo de provisão de bem-estar social. Esse tipo de trabalho abrange as tarefas domésticas; o cuidado de seus membros, especialmente os dependentes; e também os investimentos que as famílias têm de fazer no campo das relações com outras instituições, os quais lhes exigem energia, tempo e habilidades. A pertinência da adoção dessa nomenclatura associa-se, em primeiro lugar, ao fato de propor maior desconcentração das atividades que fazem parte do trabalho doméstico. Ou seja, inclui, além das tarefas domésticas e do cuidado, o tempo utilizado e o esforço desprendido pela família nas relações com as instituições. Este último item é significativo no campo da política social, pois todo processo administrativo para acessar e usufruir os serviços sociais é delegado à família. Em segundo lugar, porque a nomenclatura se refere ao trabalho não remunerado e, finalmente, porque vincula esse trabalho à família. Este, mesmo estando fortemente associado às mulheres, não pode ser reduzido a uma questão de gênero, pois, entre outras razões, não envolve apenas as mulheres e não pode ser resolvido no campo da relação de gênero. Por esses motivos é que se adota a terminologia trabalho familiar, que, de acordo com Saraceno (2013, p. 111), "comprende tutte le attività - svolte in casa anche fuori casa - necessarie per far funzionare una famiglia a livello quotidiano...”. 


\section{Família, proteção social e política social no contexto de crise do capitalismo}

Como já enunciado, com o advento do modo de produção capitalista na sociedade ocidental, a separação entre o mundo da produção e o da reprodução se apresenta como um nó problemático na contemporaneidade. Isso ocorre diante das transformações radicais nos eixos que, segundo Goldani (2002), organizam a vida social: trabalho e família. Tais mudanças, que se produzem no contexto de crise do capitalismo, têm repercutido profundamente na sociabilidade contemporânea. Nessa conjuntura, o debate sobre a família, em particular no campo da proposição de políticas sociais, tem se projetado em dois polos: um está alinhado às políticas que, através de suas formulações, proposições e oferta de benefícios e serviços sociais, se vinculam especialmente à seguridade social compreendida a partir de seu tripé básico (previdência, saúde e assistência social); outro é desenhado a partir das denominadas políticas de conciliação entre família e trabalho, que visam incrementar medidas e políticas que aliviem as tensões entre a vida laboral e as responsabilidades familiares - enfrentadas, especialmente, pelas mulheres - quando da participação no mercado de trabalho.

Em relação às políticas de seguridade social, muito tem se debatido sobre os impactos do projeto neoliberal (Behring, 2003 e 2008; Boschetti e Salvador, 2006; Pereira, 2004; Simionatto, 2002; Simionatto e Luza, 2011) na condução dessas políticas, através de uma acentuada regressão do Estado na provisão de bem-estar e com um amplo processo de privatização. Isso ocorre tanto pela via do mercado quanto da família (que se apresenta também como um importante filtro para o mercado) ou agregado ao que se tem denominado de assistencialização da política social, em que prevalece a diretriz da matricialidade sociofamiliar (Mota, 2006; Di Giovanni e Proni, 2006). Resultados de pesquisa realizada por Mioto et al. (2014) revelam que o caráter familista da política social vem se efetivando e se reforçando em vários níveis e tem se refletido em especial no campo da oferta dos serviços sociais. Isso tem se realizado basicamente por meio de: insuficiência/ausência de serviços, especialmente públicos/estatais de caráter universal; forte investimento de recursos em subsídios à oferta de serviços por entidades não 
governamentais, os quais tendem a ser focalizados, seletivos, precários e normalizantes; e também da incorporação das famílias no cotidiano dos serviços ofertados. Em relação a este último aspecto, os processos de responsabilização da família estão presentes principalmente na configuração do acesso aos serviços, no campo dos cuidados e na própria organização dos serviços e em seus processos de externalização (Britos, 2006). As instituições tendem a se apropriar do trabalho familiar por meio de práticas administrativas e de participação. Essas práticas, por um lado, impõem-se independentemente de avaliação sobre os recursos de diferentes ordens (financeiros, de tempo e emocionais) das famílias para efetuá-las; por outro lado, estão "alheias" ao conflito entre vida laboral e vida familiar que acomete seus membros (Mioto, 2012). Por exemplo, na área da saúde, observa-se que os serviços de emergência se constituem em importante porta de entrada para o atendimento da população. Isso se dá na medida em que funcionam como estratégia para o enfrentamento do conflito existente entre as demandas do emprego e as responsabilidades familiares, especialmente porque reduzem o tempo a ser despendido para o acesso e o usufruto dos serviços de saúde e porque permitem, através de seu funcionamento ininterrupto, compatibilização de horários.

Ademais, os resultados da referida pesquisa indicam que, no campo da saúde, as privatizações dos serviços levam as famílias a buscar cada vez mais alternativas no mercado. Isso representa a contraface do processo de subfinanciamento do SUS, uma vez que solapa a universalidade do acesso e incrementa os processos de externalização da assistência à saúde ao transferir a prestação dos serviços públicos para organizações comerciais, organizações não governamentais e unidades domésticas. Essas tendências acentuam e potencializam as desigualdades, na medida em que repercutem nas condições de prestação dos serviços, nas oportunidades de acesso pelos usuários e sobrecarregam as famílias. Estas, além de serem requisitadas a cumprir com as "suas obrigações" no fórum doméstico, são, cada vez mais, acionadas a se incorporar no trabalho de cuidado no próprio ambiente de prestação de serviço, e também realizam demoradas e desgastantes interlocuções com os serviços para deles usufruírem. Entrevistas com famílias e profissionais de saúde deixaram claro que os processos de responsabilização 
das famílias relacionam-se também com as expectativas das equipes de saúde, quando projetam na família o protagonismo no acompanhamento e cuidado do usuário. O cuidado, nesse contexto, é entendido como algo natural e intrínseco às famílias e é representado nas instituições pela figura do acompanhante - geralmente mulher. Entre os profissionais há um consenso de que o conjunto de ações desenvolvidas pelos familiares tem grande impacto no cotidiano dos processos de trabalho nas instituições, pois o acompanhante executa inúmeras ações que aliviam a carga de trabalho em todo o ambiente hospitalar (Mioto, 2012).

O segundo polo projetado para a discussão da família no campo da proteção social são as políticas de conciliação entre trabalho e família. De acordo com Naldini e Saraceno (2011), elas têm se tornado uma palavra de ordem no campo das políticas sociais contemporâneas, particularmente no contexto europeu. Surgem no momento em que as mulheres ascendem no mercado de trabalho e, portanto, quando é colocado em xeque o equilíbrio do "sistema família-trabalho". Esse sistema é baseado não só na separação entre casa e empresa, mas também na divisão sexual do trabalho. Inicialmente, as políticas de conciliação, segundo as autoras, tinham a finalidade de ajudar as mulheres a entrar e permanecer no mercado de trabalho e, ao mesmo tempo, responder às suas responsabilidades familiares. Porém o avanço do movimento feminista, bem como os estudos de feministas de orientação marxista já indicavam como questão central o reconhecimento do trabalho no âmbito da reprodução. Esse movimento está incorporado também na agenda da Organização Internacional do Trabalho (OIT) desde os anos 1960. A princípio, referia-se apenas ao trabalho das mulheres; atualmente, vem sendo discutido nos marcos do trabalho decente e das responsabilidades familiares (OIT, 2009).

Segundo Bruschini e Ricoldi (2009, p. 121),

apesar de as responsabilidades familiares ainda serem um encargo majoritariamente feminino, com as mudanças demográficas, econômicas e sociais das últimas décadas a tendência tem sido a de enxergar a questão como um problema da família e não somente das mulheres. 
Também Montali (2000), ao discutir a questão da família nos marcos da reestruturação produtiva dos anos 1990 no Brasil, já afirmava a impossibilidade concreta de realização do padrão de família baseado no "chefe provedor”, aquele sobre o qual se estruturou o próprio Welfare State. Tal impossibilidade pode ser confirmada por meio da tabela a seguir.

\begin{tabular}{|l|c|c|c|c|c|c|}
\hline \multicolumn{7}{|c|}{ Mulher } \\
\hline & 1970 & 1980 & 1991 & $\mathbf{2 0 0 0}$ & $\mathbf{2 0 1 0}$ \\
\hline PIA & 33.305 .630 & 44.456 .730 & 57.612 .439 & 70.058 .774 & 83.223 .618 \\
\hline PEA & 6.195 .447 & 11.842 .726 & 18.966 .712 & 30.921 .054 & 40.678 .651 \\
\hline Taxa de participação (\%) & $\mathbf{1 8 , 6}$ & $\mathbf{2 6 , 6}$ & $\mathbf{3 2 , 9}$ & $\mathbf{4 4 , 1}$ & $\mathbf{4 8 , 9}$ \\
\hline \multicolumn{7}{|c|}{} \\
\hline
\end{tabular}

Fontes: Censo Demográfico 1970 (Tabela 24, p. 93). Disponível em: < http://biblioteca.ibge.gov.br/visualizacao/periodicos/69/ cd_1970_v1_br.pdf>.

Censo Demográfico 1970 (Tabela 1.1, p. 2). Disponível em: <http://biblioteca.ibge.gov.br/visualizacao/periodicos/75/ cd_1980_v1_t5_n1_br.pdf $>$.

Censos Demográficos 1991, 2000 e 2010 (Tabela 616). SIDRA/IBGE.

Nesse sentido, Naldini e Saraceno (2011) indicam a falência do mecanismo fundamental de conciliação entre produção e reprodução, gestado no bojo do capitalismo, através da família. Segundo as autoras, no contexto capitalista, a família se conformou como o espaço dentro do qual se realiza a alocação do trabalho remunerado e do não remunerado, com base na condição de gênero. Dessa forma, tornou-se possível conjugar necessidades de renda/salário e necessidades de cuidado, ao mesmo tempo que se mantêm separadas áreas de experiências, necessidades, relações, valores e ritmo de 
tempo, potencialmente conflituosas. As autoras agregam à falência desse mecanismo dois outros fatores: o primeiro refere-se às mudanças demográficas relativas ao envelhecimento da população, as quais impõem o aumento expressivo das demandas de cuidado; o segundo, às mudanças do mundo do trabalho, que contrariam o que se dava nos anos dourados, quando a família do homem provedor se combinava ao pleno emprego e a fortes mecanismos de proteção social. Agora, as famílias se defrontam com a flexibilização das relações de trabalho, o enfraquecimento dos mecanismos de solidariedade pública e a difícil inserção dos jovens no mercado de trabalho em época de formação de famílias. Tudo isso acarreta a busca de novos mecanismos para a conciliação entre trabalho e família no momento em que se foi substituindo o modelo de família nos próprios fundamentos dos regimes de bem-estar. Esse modelo, segundo Lewis (apud Naldini e Saraceno, 2011), é baseado no adulto trabalhador, ou seja, todos os adultos do núcleo familiar são autônomos, livres economicamente, e é como se também fossem livres de qualquer responsabilidade de cuidado em relação a outras pessoas. Dessa forma, continua em aberto a questão de quem se encarrega das responsabilidades familiares, tanto dentro da família quanto nas relações entre Estado, mercado e família. Também em aberto está o problema de como essa mudança atinge os sujeitos dentro da família quando se tomam os indicadores de classe social, idade e sexo. ${ }^{7}$

No encaminhamento das políticas de conciliação entre trabalho e responsabilidades familiares na União Europeia, Naldini e Saraceno (2011) identificam tensões que se apresentam no debate entre perspectivas teóricas e políticas. Atualmente, essa discussão tem sido influenciada por organismos internacionais, o que fortalece a perspectiva do novo "liberalismo inclusivo", o qual vê no ingresso das mulheres no mercado de trabalho a solução para todos os problemas dos países desenvolvidos, como redução de pobreza, envelhecimento da população e baixa fecundidade. Assim, há um

7. Para ampliar essa discussão, é interessante a leitura de Orozco (2006) sobre a crise dos cuidados e a reorganização do sistema econômico. 
encorajamento ao ingresso de todos no mercado de trabalho, e os pobres, particularmente, são incentivados aos trabalhos de baixa qualificação e com baixos salários, sendo integrados à assistência social quando "necessário". Essa nova política tem levado ao abandono da política do "maternalismo" (reconhecimento do papel materno como fonte de direitos e proteção, especialmente para as mães sós e pobres), que marcou por muito tempo os países anglo-saxônios. Em contraponto à perspectiva do "liberalismo inclusivo", tem sido proposto um discurso alternativo, baseado no reconhecimento da importância de "políticas de cuidado" para a infância em geral. Esse discurso se concentra na defesa da educação e do bem-estar das crianças, principalmente as de tenra idade, e também na melhoria da qualidade dos serviços de educação. Nesse sentido, ele desloca o debate sobre a participação das mulheres no mercado de trabalho e incrementa a atenção com o objetivo de proporcionar a mesma oportunidade para todas as crianças, ou seja, o direito de todas elas - independentemente do corte de classe social e do status social dos pais no mercado de trabalho - terem acesso a serviços de qualidade.

De forma geral, o grande embate que se tem colocado no campo das relações entre política social e família refere-se às tendências entre uma perspectiva que persiste na ideia de manter as atividades de cuidado dentro da casa e tem redundado em um amplo processo de mercadorização e no aprofundamento da desigualdade de classe e de gênero. A outra perspectiva insiste no processo de desfamilização e desmercadorização do cuidado e, portanto, na cobertura ampla e universal de serviços sociais. ${ }^{8} \mathrm{~A}$ análise de Carloto (2012) sobre a política de assistência social brasileira chama a atenção para a insuficiência de serviços públicos na esfera dos cuidados. Essa autora afirma que tal ausência, além de penalizar principalmente as mulheres, penaliza ainda mais as pobres, quando se considera que obstaculiza a inserção e a permanência no mercado de trabalho, aumenta o tempo de trabalho não remunerado e inviabiliza a participação na esfera pública. Ainda sobre a situação brasileira, outros estudos, como o

8. Debate sobre essa questão pode ser buscado em Gama (2010), Campos e Teixeira (2010). 
de Alencar (2008 e 2010) e o de Gama (2010 e 2012), também apontam para a importância e a impossibilidade de se continuar ignorando a questão do trabalho de reprodução no campo de debate, seja do trabalho, seja da política social brasileira.

Para Saraceno (2013, p. 37), é fundamental analisar o que fazem as políticas públicas, "incluse le aspettative implicite o explicite che fomulano rispetto alle altre agenzie e istituzioni, in primis la famiglia". De acordo com ela, a primazia do Estado, característica do pacto do Welfare, naturalmente não é a única forma de redistribuição de recursos e satisfação de necessidades, porém continua sendo a mais importante do ponto de vista da igualdade entre sujeitos com recursos familiares, pessoais e de mercado diferentes.

Na América Latina, essa situação se complica, uma vez que o trabalho reprodutivo é de pouco reconhecimento social e político e, portanto, ainda não é considerado uma questão pública (Sunkel, 2006; Fontoura et al., 2010; Sorj, Fontes e Machado, 2007; Krmpotic e De Ieso, 2010). Certamente, essa situação está associada à desigualdade estrutural imperante na região, a qual é crivada por três eixos que se articulam: classe, gênero e etnia (Arriagada, 2002). Referindo-se à sociedade brasileira, Bilac (1995) afirma que, no Brasil, "as mediações entre o processo de reprodução das classes e o processo de reprodução nas classes não seriam necessariamente as mesmas, nem se estabeleceriam do mesmo modo, em todos os grupos e segmentos sociais". Isso pode ser associado às características históricas da urbanização subdesenvolvida, que colocou a solidariedade familiar como forma de enfrentamento das condições de marginalidade. Como coloca a Comissão Econômica para a América Latina e o Caribe (Cepal, 1976, p. 95),

dadas as condições criadas pela variedade de urbanização, que em forma tão característica ocorreu na maioria dos países da área, a manutenção de algumas normas sociais apoiadas em valores tradicionais da solidariedade familiar parece ter tido considerável importância não só como mecanismo para assegurar a sobrevivência em situações de subemprego, mas também para elevação e a conservação do status individual. 
No Brasil, essa condição, apesar dos avanços introduzidos com a Constituição de $1988,{ }^{9}$ vem afetando não só o circuito das relações da família com o mundo do trabalho, mas também as relações da família com os serviços sociais. Ou seja, no momento em que se aprofunda a retração do Estado na provisão de bem-estar, a família vem sendo chamada a participar intensamente dos serviços na provisão de bem-estar. No âmbito da política de saúde, a expressão mais recente dessa condição é o programa Melhor em Casa, lançado em 2011 pelo Ministério da Saúde (Mioto e Dal Prá, 2012; Mioto, Dal Prá e Gelinski, 2013). Na política de assistência social, a ênfase na matricialidade sociofamiliar tem exigido uma família participativa e investido no fortalecimento de seus vínculos e no aumento da sua capacidade protetiva. Essa ênfase é amparada, em grande medida, pelas condicionalidades do programa Bolsa Família — é desvinculada da oferta efetiva de serviços sociais e, contraditoriamente, vinculada a programas de inclusão produtiva e aumento do consumo interno.

\section{Conclusões}

À guisa de conclusão, destaca-se que o trabalho familiar constitui-se em uma questão importante no contexto contemporâneo, em especial no campo da política social, com dois polos de debate anunciados: um é vinculado às políticas de seguridade social — principalmente saúde e assistência social —, que têm se apropriado largamente do trabalho familiar; o outro, através de políticas de conciliação entre trabalho e responsabilidades familiares, tende a propor solução para o conflito entre essas duas esferas. Ou seja, enquanto a família, no campo da seguridade social, tem sido incorporada como um recurso fundamental no atendimento das necessidades

9. A Constituição de 1988 abriu importantes possibilidades para se avançar no campo da proteção social, tanto em relação às mulheres trabalhadoras quanto em relação à conciliação entre trabalho produtivo e trabalho reprodutivo. Nessa perspectiva, destaca-se o princípio de igualdade entre homens e mulheres, o avanço nos direitos sociais e a ampliação da concepção de família, que inclui tanto o núcleo familiar formado a partir da união estável entre homem e mulher quanto qualquer outra configuração formada por pais ou mães e seus descendentes, desaparecendo a noção de pátrio poder no âmbito familiar. 
humanas (principalmente na função de suprir o retraimento do Estado na garantia de direitos), no campo das políticas de conciliação entre trabalho e família, a inclusão parece ser diferente. Assim, parte-se do princípio de que, dentro do quadro atual das transformações ocorridas na família e no mundo do trabalho, é necessária a instauração de mecanismos públicos que proporcionem às famílias/mulheres condições para gerir o trabalho de reprodução e para enfrentar os problemas advindos da própria precarização do trabalho. Em outras palavras, enquanto no campo da seguridade social reafirma-se a lógica da naturalização do trabalho familiar, o campo das políticas de conciliação entre trabalho e família desnaturaliza e busca dar visibilidade a esse trabalho. No entanto, é preciso atentar para o fato de que a questão colocada, embora tenha tratamento díspar no campo da política social, não significa que o seu debate possa ser reduzido a uma questão da política social. Isso porque ela é intrínseca às próprias bases de estruturação da sociedade capitalista ocidental. Mais uma vez, adverte-se que, no sistema de produção capitalista, a cisão entre o mundo da produção e o da reprodução constitui um importante mecanismo para a própria sobrevivência e reprodução do capitalismo. Como afirma David Harvey (1982, p. 8), "a dicotomia entre o viver e o trabalhar é uma divisão artificial imposta pelo sistema capitalista". Para ele, em decorrência dessa perspectiva, embora as necessidades da força de trabalho tenham se alterado historicamente, continuam sendo atendidas, em parte, pelo "trabalho dentro das unidades familiares e, em parte, através das trocas no mercado, de salários ganhos contra mercadorias produzidas". Assim, a satisfação de tais necessidades depende tanto dos produtos da economia doméstica quanto das compras do mercado, bem como das condições ambientais, históricas e morais que definem os níveis de vida dos trabalhadores. Disso decorre o nosso entendimento de que compreender as bases em que as sociedades proporcionam a sobrevivência e o bem-estar de seus membros implica considerar todas as formas de trabalho, sejam remunerados ou não, bem como as relações que se estabelecem entre eles nos marcos da sociabilidade contemporânea.

Enfim, trazer para o debate a questão do trabalho familiar significa lançar luz sobre um aspecto da vida social que tem sido historicamente in- 
visibilizado, particularmente na América Latina, quando se discute a produção de bem-estar social e a conformação da política social. Nesse quadro é que se coloca a necessidade de discutir a incorporação da família na política social pelo viés do trabalho familiar. Não problematizar esse trabalho, seja no campo das políticas de seguridade social ou no das relações entre família e trabalho, que tem se expressado através das políticas de conciliação trabalho e família, significa não só comprometer as famílias e as suas possibilidades enquanto instância de bem-estar, mas também enfraquecer os pactos de solidariedade pública.

Recebido em 27/2/2015 - Aprovado em 23/7/2015

\section{Referências bibliográficas}

AGUIRRE, R. Las bases invisibles del bienestar social: el trabajo no remunerado en Uruguay. Montevideo: Unifem-Uruguay/Doble Clic Editoras, 2009.

ALENCAR, M. M. T. Transformações econômicas e sociais no Brasil dos anos 1990 e seu impacto no âmbito da família. In: SALES, Mione Apolinario et al. (Orgs.). Política social, família e juventude. São Paulo: Cortez, 2008. p. 61-78.

. Família, trabalho e reprodução social: limites na realidade brasileira. In:

DUARTE, M. J. O. Família, famílias: práticas sociais e conversações contemporâneas. Rio de Janeiro: Lumen Juris, 2010.

ARAÚJO, C.; SCALON, C. (Orgs.). Gênero, família e trabalho no Brasil. Rio de Janeiro: FGV, 2005.

ARRIAGADA, I. Cambios y desigualdad en las famílias latinoamericanas. Revista de la Cepal, Santiago de Chile, n. 77, p. 143-161, ago. 2002.

BATTHYÁNY, K.; SCURO, L. Uso del tiempo, cuidados y bienestar: desafíos de Uruguay y la región. Revista de Ciencias Sociales, Departamento de Sociología, ano 23, n. 27, dez. 2010. 
BEHRING, E. R. Brasil em contra-reforma: desestruturação do Estado e perda de direitos. São Paulo: Cortez, 2003.

. Brasil em contra-reforma: desestruturação do Estado e perda de direitos. 2. ed. São Paulo: Cortez, 2008.

BENERÍA, L. El debate inconcluso sobre el trabajo no remunerado. Revista Internacional del Trabajo, OIT, v. 118, n. 3, 1999.

BILAC, E. D. Sobre as transformações nas estruturas familiares no Brasil. Notas muito preliminares. In: RIBEIRO, I.; RIBEIRO, A. C. Família e processos contemporâneos: inovações culturais na sociedade brasileira. São Paulo: Loyola, 1995. p. 43-64.

BOSCHETTI, Ivanete; SALVADOR, Evilásio. Orçamento da seguridade social e política econômica: perversa alquimia. Serviço Social \& Sociedade, São Paulo, v. 87, p. 25-57, 2006.

BRASIL. Ministério da Saúde. Programa Melhor em Casa, 2012. Disponível em: $<$ www.saude.gov.br>. Acesso em: 30 abr. 2013.

BRITOS, Nora. Ámbito profesional y mundo del trabajo: políticas sociales y trabajo social en los anos noventa. Buenos Aires: Espacio Editorial, 2006.

BRUSCHINI, M. C.; RICOLDI, A. M. Família e trabalho: difícil conciliação para mães trabalhadoras de baixa renda. Cadernos de Pesquisa, São Paulo, v. 39, n. 136, p. 93-123, jan./abr. 2009.

CARLOTO, C. M. Programa Bolsa Família, cuidados e o uso do tempo das mulheres. In: ENCONTRO NACIONAL DE PESQUISADORES EM SERVIÇO SOCIAL/ ENPESS, 13., Juiz de Fora, 2012.

CARRASCO, C. La economía del cuidado: planteamiento actual y desafíos pendientes. Revista de Economía Crítica, Barcelona, n. 11, 2011.

CEPAL. Industrialização na América Latina. Urbanização na América Latina. Problema de emprego da mão de obra citadina. In: PEREIRA, L. Urbanização e subdesenvolvimento. Rio de Janeiro: Zahar, 1976.

DI GIOVANNI, Geraldo; PRONI, M.V. Metamorfose do Estado, proteção e cidadania: texto para estudo dirigido. São Paulo: MTE/Unitrabalho, 2006.

FONTOURA, N. et al. Pesquisas de uso do tempo no Brasil: contribuições para a formulação de políticas de conciliação entre trabalho, família e vida pessoal. Revista Econômica, Rio de Janeiro, v. 12, n. 1, jun. 2010. 
GAMA, Andréa de Sousa. Trabalho e responsabilidades familiares no Brasil: reflexões sobre os direitos do trabalho. Em Pauta, Rio de Janeiro, v. 10, n. 30, p. 149-168, 2012.

."Entre o trabalho e a família": contradições nas respostas públicas às configurações da divisão sexual do trabalho. In: DUARTE, M. J. O.; ALENCAR, M. M. T. Familia, famílias: práticas sociais e conversações contemporâneas. Rio de Janeiro: Lumen Juris, 2010.

GELINSKI, C. R. O.; PEREIRA, R. S. Mulher e trabalho não remunerado. Mulher e Trabalho, Porto Alegre, v. 5, p. 59-87, 2005.

GOLDANI, A. M. Família, gênero e políticas: famílias brasileiras nos anos 90 e seus desafios como fator de proteção. Revista Brasileira de Estudos de População, Rio de Janeiro, v. 19, n. 1, p. 29-48, 2002.

HARVEY, D. O trabalho, o capital e o conflito de classes entre o ambiente construído nas sociedades capitalistas avançadas. Espaço e Debates, São Paulo, ano 2, n. 7, p. 6-35, set. 1982 .

HERNÁNDEZ BELLO, A. El trabajo no remunerado de cuidado de la salud: naturalización e inequidad. Revista Gerencia y Políticas de Salud, Bogotá, v. 8, n. 17, p. 173185, jun./dez. 2009.

IASI, M. Ensaios sobre consciência e emancipação. São Paulo: Expressão Popular, 2007.

IZQUIERDO, M. J. Del sexismo y la mercantilización del cuidado a su socialización: hacia una política democrática. In: CONGRESO INTERNACIONAL SARE 2003. Cuidar cuesta: costes y beneficios del cuidado. Barcelona: Emakunde/Sare, out. 2003. p. 4-37.

IZQUIERDO, S. C. Bienestar, actividad económica y cuentas nacionales. Reflexiones en torno al concepto de trabajo productivo. Política y Sociedad, México, v. 45, n. 2, p. 151-167, 2008.

KRMPOTIC, C. S.; DE IESO, L. C. Los cuidados familiares. Aspectos de la reproducción social a la luz de la desigualdad de género. Katálysis, Florianópolis, v. 13, n. 1, p. 95-101, jan.jun. 2010.

LETABLIER, M. T. El trabajo de "cuidados" y su conceptualizacion en Europa. In: PIETRO, C. (Ed.). Trabajo, género y tiempo social. Madrid: Complutense, 2007.

MARTINEZ-FRANZONI, J. ¿Arañando bienestar? Trabajo remunerado, proteción social y familias en América Central. Buenos Aires: Clacso, 2008. 
MEIL, L. G. La sociología de la familia en España, 1978/1998. Revista Espanõla de Investigaciones Sociologicas, Madrid, CIS, n. 8, p. 173-215, 2004.

MELO, H. P.; CONSIDERA, C. M.; DI SABBATO, A. Os afazeres domésticos contam. Economia e Sociedade, Campinas, v. 16, n. 3 (31), p. 435-454, dez. 2007.

MIOTO, R. C. T. Processos de responsabilização das famílias no contexto dos serviços públicos: notas introdutórias. In: SARMENTO, Hélder Boska de Moraes (Org.). Serviço Social: questões contemporâneas. Florianópolis: Ed. da UFSC, 2012. v. 1, p. 125-138.

; SCHUTZ, F.; CAETANO, P. Família e política social: relações entre famílias e serviços de saúde. Relatório de Pesquisa. Brasília, 2014.

; DAL PRÁ, K. R. Serviços sociais e responsabilização da família: contradições da política social brasileira. In: ENCONTRO BRASILEIRO DE PESQUISADORES EM SERVIÇO SOCIAL, 12., Juiz de Fora, 2012.

; GELINSKI, C. R. O. G. El proceso de familiarización del gasto y de los cuidados en salud en Brasil. Actas del Congreso de la Red Española de Política Social, Universidad de Alcalá, Madrid, 2013. Disponível em: <http://www3.uah.es/ congresoreps2013/Paneles/panel6/htm>. Acesso em: 18 jan. 2015.

MONTALI, L. Família e trabalho na reestruturação produtiva: ausência de políticas de emprego e deterioração das condições de vida. Revista Brasileira de Ciências Sociais, São Paulo, v. 15, n. 42, fev. 2000.

MORAES, M. L. Marxismo e feminismo: afinidades e diferenças. Crítica Marxista, Campinas, n. 11, 2000.

MOTA, A. E. O fetiche da assistência social: um debate necessário. In: . O mito da assistência social. Recife: Ed. Universitária (UFPE), 2006.

NALDINI, M.; SARACENO, C. Conciliare famiglia e lavoro. Bologna: Il Mulino, 2011.

ORGANIZAÇÃO INTERNACIONAL DO TRABALHO (OIT). Trabalho e familia: rumo a novas formas de conciliação com co-responsabilidade social. Brasília: OIT, 2009.

OROZCO, A. P. Amenaza Tormenta: la crisis de los cuidados y la reorganización del sistema económico. Revista de Economía Crítica, Madrid, n. 5, p. 7-37, mar. 2006.

PAULILO, M. I. Trabalho familiar: uma categoria esquecida de análise. Estudos Feministas, Florianópolis, v. 12, n. 1, p. 229-252, jan./abr. 2004.

PEREIRA, P. A. P. Pluralismo de bem-estar ou configuração plural da política social sob o neoliberalismo. In: BOSCHETTEI, I. et al. (Orgs.). Política social: alternativas 
ao neoliberalismo. Brasília: UnB, Programa de Pós-Graduação em Política Social, Departamento de Serviço Social, 2004.

PIETRO, C. Clases de sujetos, clases de actividades y clases de tiempos: una mirada desde la perspectiva del género. In: (Ed.). Trabajo, género y tiempo social. Madrid: Complutense, 2007.

SALVADOR, A. D. Métodos e técnicas de pesquisa bibliográfica. 11. ed. Porto Alegre: Sulina, 1986.

SARACENO, C. Sociologia della famiglia. Bologna: Il Mulino,1996.

. Il Welfare: Modelli e dilemmi della cittadinanza sociale. Bologna: Il Mulino, 2013.

SECCOMBE, W. Famiglie nella tempesta: classe operaria e forme familiari dalla rivoluzione industriale al declino della fertilità. Firenze: La Nuova Italia, 1997.

SIMIONATTO, I. Mercosul e reforma do Estado: o retrocesso da seguridade social. Katálysis, Florianópolis, v. 1, n. 5, p. 33-48, 2002.

; LUZA, E. Estado e sociedade civil em tempos de contrarreforma: lógica perversa para as políticas sociais. Textos \& Contextos, Porto Alegre, v. 10, n. 2, p. 215-226, ago./dez. 2011.

SORJ, B.; FONTES, A.; MACHADO, D. C. Políticas e práticas de conciliação entre família e trabalho no Brasil. Cadernos de Pesquisa, São Paulo, v. 37, n. 132, p. 573-594, set./dez. 2007.

SUNKEL, G. El papel de la familia en la protección social. Santiago de Chile: Cepal, División de Desarollo Social, 2006. (Série Políticas Sociais, v. 120.) 